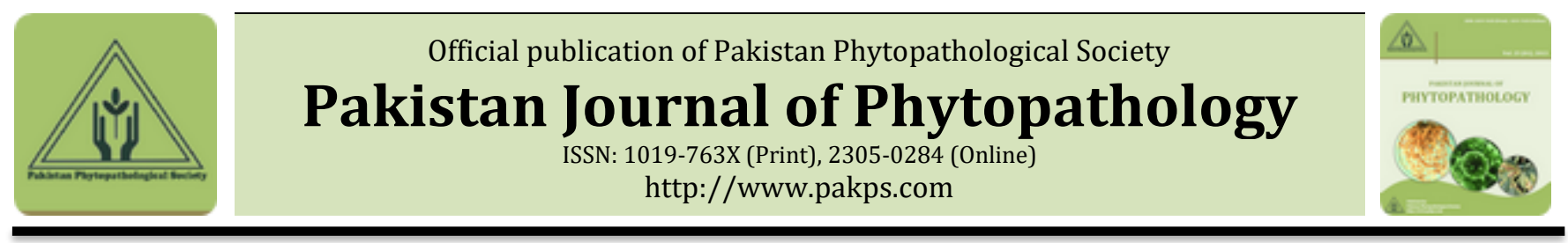

\title{
INCIDENCE OF PANTOEA AGGLOMERANS ASSOCIATED WITH BARNYARD GRASS (ECHINOCHLOA CRUSGALLI L.) IN PAKISTAN
}

\author{
aSehrish Mushtaq*, aMuhammad Shafiq, aUmmad Hussain, aFreeha Ali, aAmna Ali, aFaiza Khan, \\ bMuhammad Asim, a Muhammad S. Haider \\ a Institute of Agricultural Sciences, University of the Punjab, Quaid-e-Azam Campus, Lahore. Pakistan. \\ ${ }^{\boldsymbol{b}}$ Citrus Research Institute Sargodha, Pakistan.
}

\begin{abstract}
A B S T RA C T
Weeds are reservoirs for the survival of pathogenic microorganisms and cause of spread of infectious disease of plants through vectors. To minimize the spread of bacteria to other host crops, proper characterization is required to suggest suitable control strategy. Survey was conduct in December 2015, leaf blight was observed on barnyard grass growing in surroundings of citrus orchards located in Lahore, Pakistan. Isolation of the bacterium on nutrient agar medium was performed and their characterization based on morphological and biochemical tests. 16S rRNA was amplified directly with primers 27F/1492R, cloned and sequenced. Sequences were blast in NCBI data base which showed 99\% identity to P. agglomerans strain. A neighbor-joining tree was generated with reported bacterial strain that were most closely to isolated strain P. agglomerans (LT592133). Pathogenicity test was conducted on barnyard grass with bacterial suspensions having $1.5 \times 10^{8} \mathrm{CFU} / \mathrm{ml}$ in controlled conditions to confirm Koch's postulates. According to results this is first report on the incidence of Pantoea agglomerans on Barnyard grass in Pakistan.
\end{abstract}

Keywords: Pantoea agglomerans, pathogenicity test, barnyard grass, 16S rRNA analysis

\section{INTRODUCTION}

Barnyard grass is a specie of grass that is included in the Global Compendium of Weeds as well as among the world's worst weeds (Pheng et al., 2001). It has been stated as weed in many crops throughout tropical and temperate regions of the world. It is also considered an environmental weed that has become invasive in natural grasslands, coastal forests and spreads in Asia, Africa, Australia, Europe and America. Weeds are reservoir for majority of pathogens including bacteria that leads to the emergence of new strains of bacteria that may infect crops once a susceptible host plant is present into an agroecological system. Bacterial population from weeds should be identified to suggest some control measure,

Submitted: December 28, 2017

Revised: May 28, 2018

Accepted for Publication: May 10, 2019

* Corresponding Author:

Email: sherry.a143@gmail.com

(C) 2017 Pak. J. Phytopathol. All rights reserved. against the spread of pathogenic bacterial disease to economical important crops.

Pantoea agglomerans is a gram-negative aerobic, rod shape bacteria belongs to family Entero bacteriaceae. All species of the genus Pantoea can be isolated from different plants and soil (Andersson et al., 1999), where they can be either pathogens or nonpathogenic (Monier et al., 2005). Pantoea agglomerans cause leaf blight symptoms as necrotic lesion that appeared as water soaked or light brown to slightly reddish spots on the upper blades of the leaves, which ultimately turned into blight and then stalk rot (Morales et al., 2017). this specie of Pantoea is infectious to human which is associated with different plants. Though, this bacterium could be a reason for the spread of opportunistic infections in human with plant materials. It can be epiphyte or endophytic on different plants mostly occurs with mutualistic relationships with plants. However, this specie has also been identified as a major cause of diseases in a variety of hosts such as rice, maize, sorghum, onion, cotton, walnut, bamboo. Almost several 
of plant-pathogenic strains of $P$. agglomerans can cause tumors, which includes gall formation on table beet, an ornamental plant gypsophila, Douglas-fir, cranberry and wisteria. Currently, the reported specie has been recognized as a cause of bacterial blight disease in the edible mushroom which is cultivated in China. Various factor are involved in the mechanism of pathogenicity among strains o Pantoea agglomerans which involves the hypersensitive response, quorum sensing, phytohormones and the type three secretion system through which it inject the effector proteins into the cytosol of a plant cell and become the cause of infection in plants (Dutkiewicz et al., 2016).

\section{MATERIAL AND METHODS}

In December 2015, leaf blight was observed on barnyard grass (Echinochloa crus-galli) growing in surroundings of citrus orchards located in Lahore, Pakistan. Symptomatic leaf tissue sections of about 1 $\mathrm{cm}^{2}$ was disinfested with $1 \%$ sodium hypochlorite for two minutes followed by three subsequent washings with sterile distilled water, grinded in distilled water by using sterilized pestle and mortar. Then it was streaked on nutrient Agar medium and incubated at 30 ${ }^{\circ} \mathrm{C}$ for 24-48 Hours. After 3-4 days, bacterial colonies were observed and preceded for morphological and biochemical characterization. This strain was identified through 16S rRNA gene sequence analyses. 16S rRNA was amplified directly with primers 27F (AGAGTTTGATCMTGGCT CAG)/ 1492R (ACCTTGTTA CGACTT) cloned and sequenced (Macrogen Korea). Pathogenicity tests were performed to confirm Koch's postulates. Phylogenetic analysis were performed using Mega 6.0 software.

\section{RESULTS AND DISCUSSION}

Owing to the significance of weed hosts in the establishments of new bacteria strain, Barnyard grass display necrotic symptoms on leaves were evaluated from Lahore in December 2015. Isolated bacterial strain was preceded for morphological characterization. Morphologically Colony was off white, round, smooth and shiny with wavy margins, concave from elevations on nutrient agar medium. This bacterium was facultative, anaerobic, gram-negative, rods with three to six peritrichous flagella, 1.0 to $3.0 \times$ 0.5 to $1.0 \mu \mathrm{m}$ in size. Strain was negative for spore type, gram type, capsule stain, indole and methyl red test, hydrogen sulphide, oxidase test, growth at $2 \% \mathrm{NaCl}$, growth at 25 and $40^{\circ} \mathrm{C}$, Arginine dihydrolase, sorbitol fermentation, rhamnose fermentation but positive for motility, citrate utilization, nitrate reduction, catalase tests. Representative isolate was selected for pathogenicity tests and subsequent $16 \mathrm{~S}$ rRNA analysis. Pathogenicity tests were conducted on disease-free citrus plants (having five to six leaves) tomato, common sow, lambs quarters, and mallow weeds. Biochemical tests confirm the presence of Pantoea agglomerans. DNA was isolated from bacterial culture by CTAB method (Wilson 2001). 16S rRNA was amplified directly with primers $27 \mathrm{~F} / 1492 \mathrm{R}$, cloned and sequenced (Accession No. LT592133). BLAST of $16 \mathrm{~S}$ rDNA sequence showed $99 \%$ identity to $P$. agglomerans strain type 48b/90 (FJ756354) (Volksch et al., 2009). A tree was constructed for the isolated clone using Mega 6.0 with the reported bacterial strains using neighborjoining method. P. agglomerans (DQ307453) were most closely related to $P$. agglomerans (Gene Bank LT592133) with an average 16S rRNA sequence similarity of $99 \%$. Phylogenetic analysis grouped $P$. ananatis, P. stewartti, and P. agglomerans, P. brenneri into three clusters (Figure 1). Our sequence was clustered with group of $P$. agglomerans strains. Pathogenicity of the isolate was confirmed by injecting $\left(10^{8} \mathrm{CFU} \mathrm{mL} \mathrm{mL}^{-1}\right)$ of inoculum into 3 months old seedling stem of citrus in the greenhouse at $28 \mathrm{C}$ and $80 \%$ relative humidity and $12 \mathrm{~h}$ photoperiod were maintained. Inoculations with sterilized water served as controls and all treatments were replicated thrice. Water-soaked necrotic lesions on young leaves after 8 days post inoculation were observed, while negative control seedlings did not displayed any symptoms. Koch's postulates were confirmed through reisolation of culture, and characterize based on morphology and biochemical tests. The re isolated culture were $100 \%$ similar to their original isolate. P. agglomerans has been reported to affect other host crops, comprising, pearl millet in Zimbabwe (1997), onion in the South Africa (1981) and USA (2006), maize and Sorghum in Mexico (2007), Chinese taro in Brazil (2007), V. angularis in china (2015), onion in the United States (Tho et al., 2015) and cotton in China (Ren et al., 2008). $P$. agglomerans also found widely in nature on leaves, fruits, and the seeds of many crops and is a known endophyte (Feng et al., 2006). 


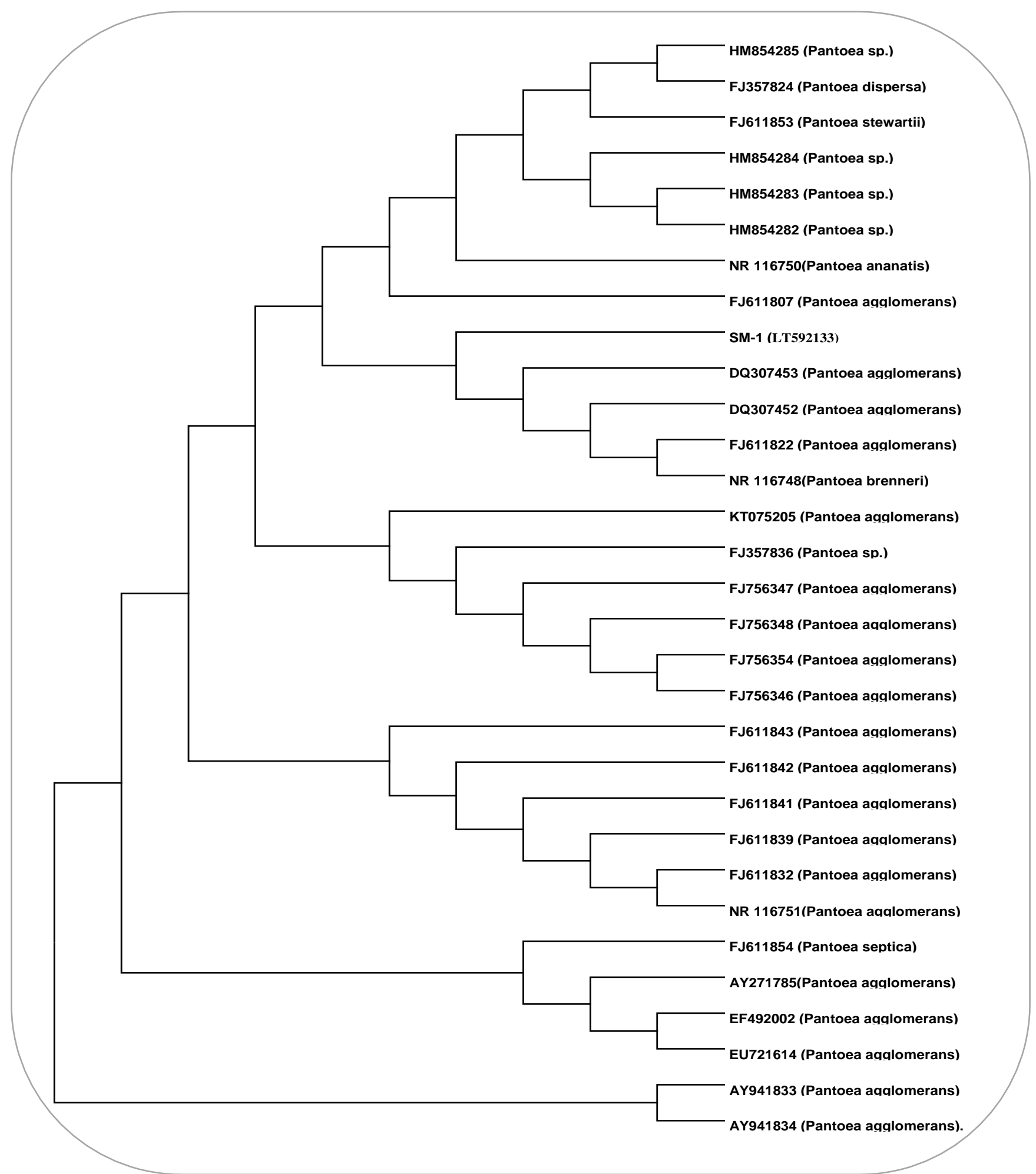

Figure 1. Phylogenetic tree constructed with sequences of the 16S rRNA regions of Pantoea agglomerans bacteria isolated from barnyard grass and sequences from GenBank (indicated by accession number), using the neighbor-joining method.

However, to our understanding, this is the first report on the incidence of $P$. agglomerans associated with leaf of barnyard grass in Lahore Pakistan. We isolated this pathogen strain of bacterium from grass that could be a source of infection for other economically important crops. Management of this grass type weed should be 
planned in order to limit the spread of this bacterium to other hosts.

This bacterium culture was submitted to First fungal culture bank of Pakistan with accession 637.

\section{REFERENCES}

Andersson, A. M., N. Weiss, F. Rainey and M. S. SalkinojaSalonen. 1999. Dust-borne bacteria in animal sheds, schools and children's day care centres. Journal of Applied Microbiology, 86: 622-634.

Dutkiewicz, J., B. Mackiewicz, M. Kinga Lemieszek, M. Golec and J. Milanowski. 2016. Pantoea agglomerans: a mysterious bacterium of evil and good. Part III. Deleterious effects: infections of humans, animals and plants. Annals of Agricultural and Environmental Medicine, 23: 197-205.

Feng, Y., D. Shen and W. Song. 2006. Rice endophyte Pantoea agglomerans YS19 promotes host plant growth and affects allocations of host photosynthates. Journal of Applied Microbiology, 100: 938-945.

Monier, J. M. and S. E. Lindow. 2005. Aggregates of Resident Bacteria Facilitate Survival of Immigrant Bacteria on Leaf Surfaces. Microbial Ecology, 49: 343-352.
Morales-Valenzuela, G., H. Silva-Rojas and D. OchoaMartínez. 2017. First report of Pantoea agglomerans causing leaf blight and vascular wilt in maize and sorghum in Mexico. Journal of Plant Diseases and Protection, 47.

Pheng, S. 2001. Response of two rice cultivars to the competition of Echinochloa crus-galli. International Rice Research Notes: 36-37.

Ren, Y. Z., Y. Q. Liu, S. L. Ding, G. Y. Li and H. Zhang. 2008. First Report of Boll Rot of Cotton Caused by Pantoea agglomerans in China. Plant Disease, 92: 1364-1364.

Tho, K. E., P. Wiriyajitsomboon and M. K. Hausbeck. 2015. First Report of Pantoea agglomerans Causing Onion Leaf Blight and Bulb Rot in Michigan. Plant Disease, 99: 1034-1034.

Völksch, B., S. Thon, I. D. Jacobsen and M. Gube. 2009. Polyphasic study of plant- and clinic-associated Pantoea agglomerans strains reveals indistinguishable virulence potential. Infection, Genetics and Evolution, 9: 1381-1391.

Wilson, K. 2001. Preparation of genomic DNA from bacteria. Current protocols in molecular biology, 56: 2.4. 1-2.4. 5 . 